\title{
Adsorption mechanism of selenate and selenite on the binary oxide systems
}

\author{
Ya Ting Chan ${ }^{a}$, Wen Hui Kuan ${ }^{b}$, Tsan Yao Chen ${ }^{c}$, Ming Kuang Wang ${ }^{a, *}$ \\ aDepartment of Agricultural Chemistry, National Taiwan University, Taipei, 10617, Taiwan \\ ${ }^{b}$ Department of Environmental and Safety Engineering, Ming-Chi University of Technology, Taipei County, 243, Taiwan \\ ${ }^{\mathrm{c} D e p a r t m e n t}$ of Engineering and System Sciences, National Tsing Hua University, Hsin-Chu, 30043, Taiwan
}

\section{A R T I C L E I N F O}

\section{Article history:}

Received 6 January 2009

Received in revised form

29 June 2009

Accepted 30 June 2009

Published online 4 July 2009

\section{Keywords:}

Binary oxide systems

Selenium oxyanions

Pseudo-second-order kinetic model

$\mathrm{X}$-ray absorption spectroscopy (XAS)

\begin{abstract}
A B S T R A C T
Removal of selenium oxyanions by the binary oxide systems, Al- or Fe-oxides mixed with $\mathrm{X}$-ray noncrystalline $\mathrm{SiO}_{2}$, was previously not well understood. This study evaluates the adsorption capacity and kinetics of selenium oxyanions by different metal hydroxides onto $\mathrm{SiO}_{2}$, and uses X-ray absorption spectroscopy (XAS) to assess the interaction between selenium oxyanions and the sorbents at $\mathrm{pH}$ 5.0. The binary oxide systems of $\mathrm{Al}$ (III)- or $\mathrm{Fe}(\mathrm{III})$-oxides mixed with $\mathrm{SiO}_{2}$ were prepared, and were characterized for their surface area, point of zero charge (PZC), $\mathrm{pH}$ envelopes, $\mathrm{X}$-ray diffraction analysis (XRD), and then macroscale adsorption isotherm and kinetics of selenite and selenate, micro-scale adsorption XAS. The adsorption capacity of selenite and selenate on $\mathrm{Al}(\mathrm{III}) / \mathrm{SiO}_{2}$ is greater than on $\mathrm{Fe}(\mathrm{III}) / \mathrm{SiO}_{2}$. Adsorption isothermal and kinetic data of selenium can be well fitted to the Langmuir isotherm and pseudo-second-order kinetic models. Based on simple geometrical constraints, selenite on both the binary oxide systems forms bidentate inner-sphere surface complexes, and selenate on $\mathrm{Fe}(\mathrm{III}) / \mathrm{SiO}_{2}$ forms stronger complexes than on $\mathrm{Al}$ (III)/ $\mathrm{SiO}_{2}$.
\end{abstract}

(c) 2009 Elsevier Ltd. All rights reserved.

\section{Introduction}

Selenium (Se) is an essential micronutrient for humans and animals, but both Se toxicity and Se deficiency occur in different parts of the world (Frankenberger and Benson, 1994). Selenium can increase activity of the free hydroxyl radicals $(\mathrm{OH}-)$ that cause high oxidation stress harmful to living beings (Zhao et al., 2008). The essential or toxic character of Se in living beings depends not only on its concentration in the circumstances, but also on the chemical compound, which directly affects absorption and bioavailability (Mikkelsen et al., 1989; Lenz et al., 2008). Selenate and selenite are the dominant species in aqueous systems (Jacobs, 1989), however, selenite is easily adsorbed by soil minerals and a higher concentration of selenate in industrial waste water is the major selenium compound polluting waters.

Aluminum, iron, and silica oxides are ubiquitous minerals in the earth's crust and they are usually employed in removing the pollutants in waters, because Al- and Fe-oxides have high surface areas and point of zero charge (i.e., 8-9.2) (Sparks, 2003). However, single oxide minerals are scarcer than binary oxide minerals in natural environments. The interaction of particles in binary oxide systems could influence the adsorption mechanism of adsorbents (Honeyman, 1984; Goh et al., 2008; Zhang et al., 2008). Lo and Chen (1997) and Kuan et al. (1998) showed that the adsorption capacity of selenium oxyanions on $\mathrm{Al}$ - and Fe-oxides coating quartz sands was about 1.1-1.5 mg Se per gram quartz. Kuan et al.

\footnotetext{
* Corresponding author. Tel.: +8862 3366 4808; fax: +8862 23660751.

E-mail address: mkwang@ntu.edu.tw (M.K. Wang).

0043-1354/\$ - see front matter ( 2009 Elsevier Ltd. All rights reserved. doi:10.1016/j.watres.2009.06.056
} 
(2004) reported Al-Si complexation and precipitate forms on the amorphous $\mathrm{SiO}_{2}$ surfaces, and discrete $\mathrm{Fe}(\mathrm{OH})_{3}$ particles form in $\mathrm{Fe}(\mathrm{OH})_{3} / \mathrm{SiO}_{2}$ (Meng and Letterman, 1993, 1996). Therefore, it is necessary to study the adsorption capacities and mechanisms of selenate and selenite by the binary oxide systems, $\mathrm{Al}(\mathrm{III})$ - or $\mathrm{Fe}(\mathrm{III})$-oxides mixed with $\mathrm{X}$-ray noncrystalline $\mathrm{SiO}_{2}$ surfaces.

$\mathrm{X}$-ray absorption spectroscopic studies provide information to help understand the interaction between oxyanions and mineral surfaces, and this information can also improve both theoretical and practical understanding of surface complexation reactions (Sparks, 2003). Hayes et al. (1987) previously compared selenate and selenite adsorption on various mineral surfaces and showed that selenate generally formed relatively weakly-bound complexes, while selenite formed stronger complexes. The surface structure of Fe-oxides can strongly affect their surface chemistry and reactivity with oxyanions. For example, sulfate formed inner-sphere monodentate complexes on a hematite surface (Hug, 1997), but it can be formed as inner- and outer-sphere complexes on goethite (wijnja and Schulthess, 2000). However, since $\mathrm{pH}$ values can strongly affect surface properties of Feoxides and oxyanions, it is necessary to discuss the change of mineral surfaces and oxyanions at different $\mathrm{pH}$ values. Manceau and Charlet (1994) reported that the changes in surface structure of HFO, goethite, and akaganeite led to different ratios of edge and corner sharing surface complexes for arsenate, selenate, and selenite at acidic pH. Peak (2006) reported that adsorption mechanisms of selenium oxyanions on mineral surfaces are strongly influenced by sorbent surface properties, and observed that selenite forms outer- and innersphere complexes on hydrous aluminum oxides, while hydrous aluminum oxides form outer-sphere complexes with sulfate and selenate, but inner-sphere monodentate surface complexes are formed between sulfate and selenate and $\alpha-\mathrm{Al}_{2} \mathrm{O}_{3}$. The overall conclusion is that selenite forms innersphere complexes on aluminum oxide minerals and selenate forms more outer- and less inner-sphere complexes. However, there have been few studies using XAS to examine the interactions of amorphous binary oxide systems and oxyanions.

The objectives of this study were to evaluate the adsorption capacity and kinetics of selenium oxyanions by the binary oxide systems, and to understand the interaction between selenium oxyanions and the adsorbents using XAS.

\section{Materials and methods}

\subsection{Preparation and characterization of the binary oxide systems}

The binary oxide systems of $\mathrm{Al}$ (III) or $\mathrm{Fe}(\mathrm{III})$ mixed with X-ray noncrystalline $\mathrm{SiO}_{2}$ were carried out in 1-L polypropylene bottles (with caps). The silica $\left(\mathrm{SiO}_{2}\right)$ purchased from $\mathrm{Cab}-\mathrm{O}-\mathrm{Sil}$ M5 (Cabot Corp., Tuscolca, IL) was an X-ray noncrystalline and fine silica with BET surface area of $200 \pm 25 \mathrm{~m}^{2} \mathrm{~g}^{-1}$ (Kuan et al., 2004). Before synthesis of the binary oxide systems, the suspension of $\mathrm{SiO}_{2}$ was aged at $25^{\circ} \mathrm{C}$ under an $\mathrm{N}_{2}$ atmosphere for $24 \mathrm{~h}$. The concentrations of binary oxide suspensions were $5 \times 10^{-3} \mathrm{M}$ for $\mathrm{Al}\left(\mathrm{NO}_{3}\right)_{3}$ or $\mathrm{Fe}\left(\mathrm{NO}_{3}\right)_{3}$ mixed with $1 \mathrm{~g} \mathrm{~L}^{-1} \mathrm{SiO}_{2}$ at
pH 5.0, monitoring with pH-stat (TIM865 Titration Manager, Radiometer Analytical). The suspensions of the binary oxide systems were synthesized at $25^{\circ} \mathrm{C}$ for sorbents in the study, adjusted to the desired $\mathrm{pH}$ by $\mathrm{NaOH}$ and $\mathrm{HNO}_{3}$ solutions, and shaken at $300 \mathrm{rpm}$ for $24 \mathrm{~h}$. After the synthesis process, a subsample collected from the suspension was centrifuged (Hitachi, 18PR-52) at 21,400 $\times g$ for $15 \mathrm{~min}$. The precipitate was washed several times with double deionized water (DDW) and freeze-dried (Millitorr Elemech FD-101) prior to X-ray and specific surface area analyses.

The precipitates prepared at various $\mathrm{pH}$ were characterized by X-ray diffraction (XRD). The samples were examined with an X-ray diffractometer (Rigaku Miniflex) using $\mathrm{CuK} \alpha$ radiation generated at $30 \mathrm{KV}$ and $15 \mathrm{~mA}$. The specific surface area of the binary oxide systems was determined by a specific area (Micrometry, Tristar, FL), using the $\mathrm{N}_{2}$-BET method. The Zetasizer (Malvern Zetasizer $3000 \mathrm{HS}$ ) was used to determine the PZC by the zeta potential function of $\mathrm{pH}$ in $0.01 \mathrm{M} \mathrm{NaNO}_{3}$.

\subsection{Adsorption experiments}

All adsorption experiments were carried out at $25^{\circ} \mathrm{C}$, and the background electrolyte concentrations were $0.1,0.01$ and $0.001 \mathrm{M} \mathrm{NaNO}_{3}$ solution, as monitored by $\mathrm{pH}$-stat. Sample $\mathrm{pH}$ was adjusted by $\mathrm{HNO}_{3}$ or $\mathrm{NaOH}$ for the entire reaction process. After all reactions, the suspensions were passed through a membrane filter (Millipore filter, $0.22 \mu \mathrm{m}$ ), and then the filtrates were analyzed by inductively coupled plasma atomic emission spectrometry (ICP-AES, Perkin Elmer, Optima 2000DV). The selenite solutions had already been analyzed by ion chromatography (IC), and we observed no selenite oxidizing to selenate during that operation. Besides that, our sample solutions were analyzed as soon as possible and all samples were kept in a $4{ }^{\circ} \mathrm{C}$ refrigerator. Our XANES results showed that no oxidizing occurs. Thus, analyzing the solutions by ICP-AES is more efficient.

\subsection{Equilibrium adsorption}

For the pH-edge experiment, the initial concentration of selenium oxyanions was $1 \mathrm{mM}$, and the $\mathrm{pH}$ of the binary oxide suspensions was maintained within the range of $2-10$. The adsorption isotherm was studied by $0-3 \mathrm{mM}$ selenium oxyanions reacted with the binary oxide systems at $25^{\circ} \mathrm{C}$ and at $\mathrm{pH} 5$ for $24 \mathrm{~h}$. The isothermal results were fitted by Langmuir isotherm, described by Eq. (1):

$\mathrm{Q}_{\mathrm{e}}=\frac{\mathrm{Q}_{\mathrm{m}} \mathrm{K}_{\mathrm{L}} \mathrm{C}_{\mathrm{e}}}{1+\mathrm{K}_{\mathrm{L}} \mathrm{C}_{\mathrm{e}}}$

where $C_{e}$ is the equilibrium concentration $\left(\mathrm{mg} \mathrm{L}^{-1}\right)$ in solution, $Q_{e}$ is the amount of selenite and selenate adsorbed at equilibrium $\left(\mathrm{mg} \mathrm{g}^{-1}\right)$, and $\mathrm{K}_{\mathrm{L}}$ is the Langmuir constants related to adsorption capacity and energy of adsorption, respectively.

\subsection{Adsorption kinetics}

For adsorption kinetic experiments, the initial concentration of selenite was $1 \mathrm{mM}$, and selenate was $0.15 \mathrm{mM}$ to react with the binary oxide systems, individually. The suspensions were set at pH 5.0 and shaken at $3000 \mathrm{rpm}$ for $240 \mathrm{~min}$. Subsamples 
were taken at different times. The pseudo-second-order kinetic model can be solved with Eq. (2). The kinetic rate equation is expressed as follows:

$\mathrm{d} q_{\mathrm{t}} / \mathrm{dt}=k_{2}\left(q_{\mathrm{eq}}-q_{\mathrm{t}}\right)^{2}$

where $q_{\mathrm{eq}}$ is the sorption capacity at equilibrium and $q_{\mathrm{t}}$ is the solid-phase loading of selenium at time t. $k_{2}\left(\mathrm{~g} \mathrm{mg}^{-1} \mathrm{~h}^{-1}\right)$ represents the pseudo-second-order rate constant for the kinetic model (Jang et al., 2003; Saha et al., 2004). By integrating Eq. (2) with the boundary conditions of $q_{t}=0$ at $t=0$ and $q_{t}=q_{t}$ at $t=t$, the following linear equation can be obtained:

$\frac{\mathrm{t}}{q_{\mathrm{t}}}=\frac{1}{\mathrm{~V}_{0}}+\frac{1}{q_{\mathrm{eq}}} \mathrm{t}$

$\mathrm{V}_{0}=k_{2} q_{\mathrm{eq}}^{2}$

where $V_{0}\left(\mathrm{mg} \mathrm{g}^{-1} \mathrm{~h}^{-1}\right)$ is the initial sorption rate. Therefore, the $V_{0}$ and $q_{\text {eq }}$ values of kinetic tests can be determined experimentally by plotting $t / q_{t}$ versus $t$.

\subsection{X-ray absorption spectroscopy analysis}

Samples for XAS analysis were obtained by mixing the binary oxide systems suspensions with $10^{-3} \mathrm{M}$ selenium oxyanions solution at $\mathrm{pH} 5.0$ (adjusted by $\mathrm{NaOH}$ or $\mathrm{HNO}_{3}$ solution) in $0.01 \mathrm{M} \mathrm{NaNO}_{3}$ solution. After being shaken for 1 day, the sample suspensions were centrifuged at 21,400 $\times g$ for $20 \mathrm{~min}$, and the paste washed several times by DDW to remove excess salts. XAS data included X-ray absorption near-edge structures (XANES) and extended X-ray absorption fine structure (EXAFS) spectroscopy at the Se K-edge $(12.658 \mathrm{keV})$ were collected on a Wiggler 20 beamline BL-17C at the National Synchrotron Radiation Research Center (NSRRC), Hsin-Chu, Taiwan. The electron storage ring operated at $1.5 \mathrm{GeV}$ with a fixed current of $250 \mathrm{~mA}$. The K-edge spectra of Se reacted with the binary oxide systems were recorded in transmission and fluorescence mode, respectively, and absorbance of the incident X-rays was collected by the ionization chambers $I_{t}$ and $\mathrm{I}_{\mathrm{f}}$ (Lytle Detector) (Lytle et al., 1984), separately. In order to attenuate scattered principle energy X-rays from entering the fluorescence detector, soller slits, and an absorbing filter (As for Se atom) were placed between sample and $\mathrm{I}_{\mathrm{f}}$ detector. The experiments were carried out from 12.63 to $12.70 \mathrm{keV}$ at ambient temperature. In addition, the $\mathrm{Au} \mathrm{L}_{3}$-edge spectrum was monitored by the $\mathrm{I}_{\mathrm{r}}$ chamber simultaneously with $\mathrm{I}_{\mathrm{t}}$ and $\mathrm{I}_{\mathrm{f}}$ chambers, serving as the reference to calibrate energy shift due to monochromator drifts.

The XAS data was normalized with careful energy calibration by the standard strategies (Koningsberger and Prins, 1998). In addition, the IFEFFIT package, including Athena and Artemis was used for various data processing operations and analysis of the EXAFS spectra (Newville, 2001; Ravel and Newville, 2005). All of the XAS were normalized by Athena in the ifeffit package, transformed from electron energy to photoelectron wave number $\left(k, \AA^{-1}\right)$ and weighted by $k^{3}$ to generate $k^{3} \phi(\mathrm{k})$ spectra to better demonstrate the contribution of different shells of the EXAFS oscillation function. Fourier transformation (FT) was further processed to produce radial structure functions (RSF). The FEFF8.2 program (Cernohorsky, 1960; Rehr and Albers, 2000; Ankudinov et al., 1998) was employed to create theoretical phases and amplitude functions representing photoelectron scattering paths of Se-O by inputting standard structure parameters of reference $\mathrm{Na}_{2} \mathrm{SeO}_{4}$ and $\mathrm{NaHSeO}_{3}$ from the Inorganic Crystallography Standard Databases (Inorganic Crystal Structure Database, 1981). The model fitting was conducted by the Artemis program, producing structure parameters such as coordination number $(\mathrm{CN})$, interatomic distance $(\mathrm{R})$, and Debye-Waller factor $\left(\sigma^{2}\right)$. The phase and amplitude shift of EXAFS spectra between local structure of the experimental sample and the theoretical atomic model were adjusted by Debye-Waller factors and amplitude reduction factor. A fixed value of 0.85 was used for the global amplitude reduction factor $\left(S_{0}^{2}\right)$.

\section{Results and discussion}

\subsection{Characterization of the binary oxide systems}

X-ray diffraction patterns show that both $\mathrm{Al}(\mathrm{III}) / \mathrm{SiO}_{2}$ and $\mathrm{Fe}(\mathrm{III}) / \mathrm{SiO}_{2}$ are X-ray noncrystalline mixed oxides at $\mathrm{pH}$ 5.0. The BET surface area of $\mathrm{Al}(\mathrm{III}) / \mathrm{SiO}_{2}$ is decreased to less than that of X-ray noncrystalline silica oxide $\left(\mathrm{SiO}_{2}\right)$, however, that of $\mathrm{Fe}(\mathrm{III}) / \mathrm{SiO}_{2}$ is increased (Table 1). Stumm and Wollast (1990) reported that a surface-coordinated metal ion, such as $\mathrm{Cu}$ (II) or $\mathrm{Al}(\mathrm{III})$, can block an oxide surface group, and the passive $\mathrm{Al}$ hydroxide inhibited the corrosion of the $\mathrm{SiO}_{2(\mathrm{~s})}$ surface by $\mathrm{OH}^{-}$ ions, Al-oxide particles may block the surface pores of silica oxide. Meng and Letterman $(1993,1996)$ reported discrete $\mathrm{Fe}(\mathrm{OH})_{3}$ particles formed in $\mathrm{Fe}(\mathrm{OH})_{3} / \mathrm{SiO}_{2}$, and discrete $\mathrm{Fe}(\mathrm{OH})_{3}$ particles increase the total surface area of the binary oxide systems. The surface charge of both binary oxide systems decreases with increasing $\mathrm{pH}$ value because of increasing $\mathrm{OH}^{-}$ ions (Fig. 1). The zeta potential of $\mathrm{Fe}(\mathrm{III}) / \mathrm{SiO}_{2}$ is less than $\mathrm{Al}(\mathrm{III}) /$ $\mathrm{SiO}_{2}$, and Meng and Letterman (1993) reported the zeta potential of $\mathrm{Fe}(\mathrm{III}) / \mathrm{SiO}_{2}$ as the overall results contributed by negatively charged $\mathrm{SiO}_{2}$ and positively charged $\mathrm{Fe}(\mathrm{OH})_{3}$. The silicate adsorption on $\mathrm{Fe}(\mathrm{OH})_{3}$ may decrease the surface potential of $\mathrm{Fe}(\mathrm{OH})_{3}$. Stumm (1992) reported that the $\mathrm{pH}_{\mathrm{zpc}}$ range of aluminum and iron oxides is 7.8-9.1, however, the interaction of $\mathrm{Al}$ with amorphous silica suggests $\mathrm{Al}$ has covered the $\mathrm{SiO}_{2}$ particles, and the negative silica sites could not cause the $\mathrm{pH}_{\text {zpc }}$ of $\mathrm{Al}(\mathrm{III}) / \mathrm{SiO}_{2}$ to be less than 9.1 (Kuan et al., 2004), thus the $\mathrm{pH}_{\text {zpc }}$ of the $\mathrm{Fe}(\mathrm{III}) / \mathrm{SiO}_{2}$ system is lower than $\mathrm{Al}(\mathrm{III}) / \mathrm{SiO}_{2}$.

Table 1 - The surface area and pore size of the binary oxide systems synthesized at pH 5.0 and X-ray noncrystalline silica oxide.

System BET surface area $\left(\mathrm{m}^{2} \mathrm{~g}^{-1}\right)$ Average pore size $(\mathrm{nm})$

$\begin{array}{lll}\mathrm{Al}(\mathrm{III}) / \mathrm{SiO}_{2}, \text { pH } 5.0 & 157 & 36 \\ \mathrm{Al}(\mathrm{III}) / \mathrm{SiO}_{2}, \text { pH } 8.0 & 188 & 29 \\ \mathrm{Fe}(\mathrm{III}) / \mathrm{SiO}_{2}, \text { pH } 5.0 & 249 & 22 \\ \mathrm{Fe}(\mathrm{III}) / \mathrm{SiO}_{2} \text {, pH } 8.0 & 247 & 21\end{array}$

The BET surface area of $\mathrm{SiO}_{2}$ is $200 \mathrm{~m}^{2} \mathrm{~g}^{-1}$ (Kuan et al., 2004). 


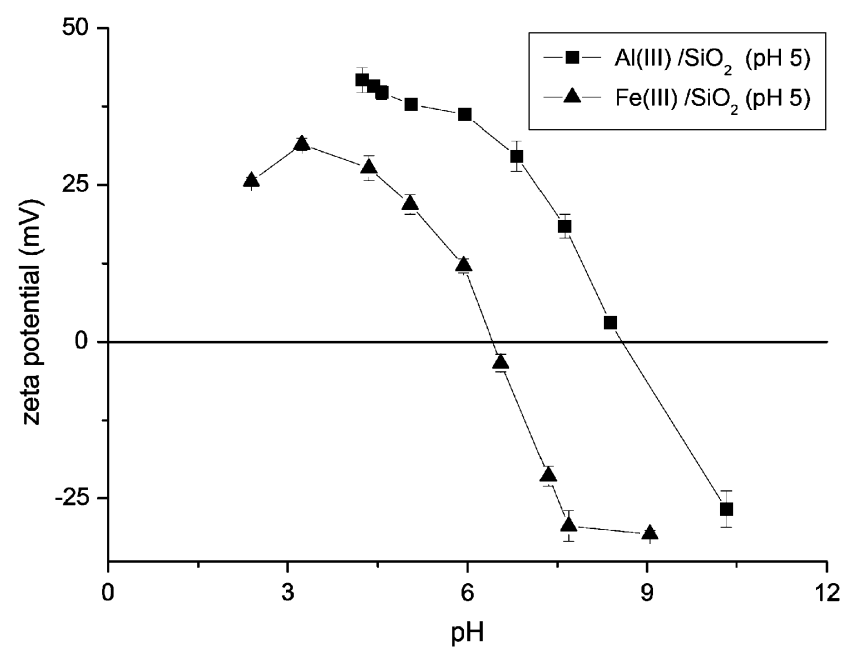

Fig. 1 - Zeta potential of the different binary oxide systems changes at different $\mathrm{pH}$ in $0.01 \mathrm{M} \mathrm{NaNO}_{3}$.

\subsection{Equilibrium adsorption}

3.2.1. $\quad \mathrm{H}$-adsorption envelopes

For $\mathrm{Al}(\mathrm{III}) / \mathrm{SiO}_{2}$ and $\mathrm{Fe}(\mathrm{III}) / \mathrm{SiO}_{2}$ prepared at $25^{\circ} \mathrm{C}, \mathrm{pH} 5.0$, the amount of selenium oxyanions adsorbed by the binary oxide systems surface is dependent on the anionic characteristics and the type of adsorption sites. To determine the optimum
$\mathrm{pH}$ for adsorption of selenium over the binary oxide systems, adsorption of selenium oxyanions as a function of $\mathrm{pH}$ was studied. Removal of selenium in the range of $\mathrm{pH} 2-12$ is shown in Fig. 2. The removal selenium efficiencies of both binary oxide systems decreases with increasing $\mathrm{pH}$ value. However, the amphoteric effect of aluminum and negative surface charge of $\mathrm{SiO}_{2}$ reduce the amounts of removal selenium oxyanions amount in the $\mathrm{Al}(\mathrm{III}) / \mathrm{SiO}_{2}$ system at $\mathrm{pH}<4.0$. When the $\mathrm{pH}$ value is increased, the $\mathrm{OH}^{-}$ions can compete with selenium oxyanions for fixed surface adsorption sites. The highest removal efficiency of selenite and selenate for both binary oxide systems is around $\mathrm{pH} 4.0$, while $\mathrm{Al}^{3+}$ is dissolved in the range of $\mathrm{pH}<4.0$. Ghosh et al. (1994) observed the removal was $100 \%$ at a pH of 5.5 or less for all initial concentrations of selenite on hydrous alumina, and virtually all of the selenite was adsorbed, even at pHs higher than the PZC (8.1) of alumina. However, the adsorption of selenate was more strongly dependent on $\mathrm{pH}$ than that of selenite. Jordan et al. (2009a) reported sorption of selenite onto magnetite decreases when the $\mathrm{pH}$ increases. Jordan et al. (2009b) reported that selenite adsorption onto hematite depended on the $\mathrm{pH}$ of the suspension, and the maximum sorption of selenite is in the acidic $\mathrm{pH}$ range. Sorption of selenite onto hematite decreases with increasing $\mathrm{pH}$.

At any given $\mathrm{pH}$ value, both the binary oxide systems have higher affinities for selenite than for selenate, and the selenium oxyanion removal capacity of the binary oxide systems is strongly influenced by the surface charge and the environmental $\mathrm{pH}$. This is consistent with the results derived from
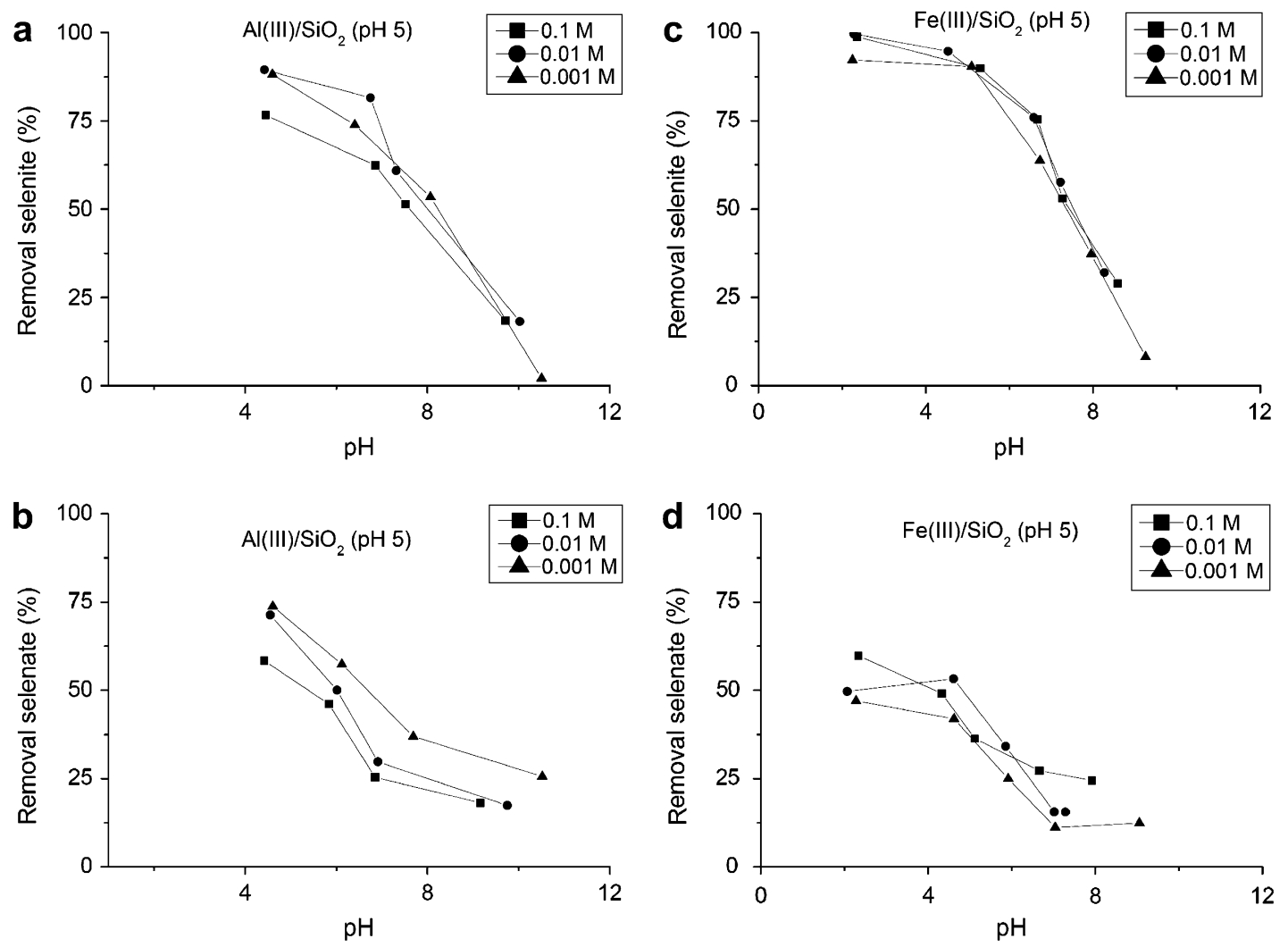

Fig. 2 - The pH adsorption edge of (a) selenite, (b) selenate on $\mathrm{Al}(\mathrm{III}) / \mathrm{SiO}_{2}$ and (c) selenite, (d) selenate on $\mathrm{Fe}(\mathrm{III}) / \mathrm{SiO}{ }_{2}$ at $\mathrm{pH} 5.0$ in different concentration of the background electrolytes. 
distinguishing various anion affinities based on the first acidity constant (Hayes, 1987; Hayes et al., 1988). Furthermore, removal of selenite remained effective when the system $\mathrm{pH}$ is high, suggesting that strong complexation occurs between selenite and both binary oxide surfaces.

The $\mathrm{pH}$ adsorption envelope of selenate on both binary oxide systems is affected by the concentration of the background electrolyte, as shown by experimental evidence, but selenite is not. The selenite and selenate adsorption by Feoxides both formed inner-sphere complexes, which was provided by the EXAFS (Hayes et al., 1988). There is no doubt that selenium adsorption on $\mathrm{Fe}(\mathrm{III}) / \mathrm{SiO}_{2}$ is not influenced by the electrolyte solutions. Peak and Sparks (2002) indicated that selenate forms only inner-sphere surface complexes on hematite but forms a mixture of outer- and inner-sphere surface complexes on goethite and HFO. The selenate adsorption mechanism is strongly affected by both $\mathrm{pH}$ and ionic strength. Although the adsorption envelope of both selenite and selenate are dependent on electrolyte concentration for the Al system in previous studies, Ghosh et al. (1994) observed the removal was $100 \%$ at a pH of 5.5 or less for all initial concentrations of selenite on hydrous alumina. At very low ratios, virtually all of the selenite was adsorbed, even at pHs higher than the PZC (8.1) of alumina. And the adsorption of selenate was more strongly dependent on $\mathrm{pH}$ than that of selenite. Peak (2006) and Peak et al. (2006) reported that selenite adsorption by hydroxyaluminum and hydroxyaluminosilicate formed both inner-sphere and outer-sphere complexes, selenate formed outer-sphere complexes with hydroxyaluminum, and selenate formed inner-sphere complexes with $\alpha-\mathrm{Al}_{2} \mathrm{O}_{3}$. It may be argued that selenium adsorption by $\mathrm{Al}(\mathrm{III}) / \mathrm{SiO}_{2}$ formed outer-sphere or innersphere complexes. However, selenium adsorption may be influenced by the electrolyte solutions in $\mathrm{Al}(\mathrm{III}) / \mathrm{SiO}_{2}$. From our EXAFS results, selenite on $\mathrm{Al}(\mathrm{III}) / \mathrm{SiO}_{2}$ formed inner-sphere complexes. Although Fig. 2 showed that selenite adsorption on $\mathrm{Al}(\mathrm{III}) / \mathrm{SiO}_{2}$ was affected by electrolyte concentrations in the range of $\mathrm{pH} 4-6$, the effect was not significant with increasing $\mathrm{pH}$. Hayes (1987) reported that selenite adsorbed onto the adsorbent, goethite $(\alpha-\mathrm{FeOOH})$, forms an innersphere complex, and selenate forms a weak outer-sphere, and then selenate on adsorbents is affected by lytropic effect in the electric double layer theory. Fig. 2 shows that the removal efficiencies of selenite and selenate on $\mathrm{Al}(\mathrm{III}) / \mathrm{SiO}_{2}$ are greater than on $\mathrm{Fe}(\mathrm{III}) / \mathrm{SiO}_{2}$ in the $\mathrm{Al}(\mathrm{III}) / \mathrm{SiO}_{2}$ system. When the basic solution was added into the $\mathrm{Al}(\mathrm{III}) / \mathrm{SiO}_{2}$ system, $\mathrm{Al}$ formed complexes with $\mathrm{SiO}_{2}$ to increase the adsorption sites on the negatively charged surface of $\mathrm{SiO}_{2}$. Thus a $\mathrm{pH} 5.0$ and $0.01 \mathrm{M}$ electrolyte solution was chosen for isothermal, kinetics, and desorption experiments.

\subsubsection{Adsorption isotherms}

To investigate the adsorption capacity, a series of selenite and selenate solutions were shaken with both the binary oxide systems that were prepared at $\mathrm{pH} 5.0$ for $24 \mathrm{~h}$. Adsorption data is fitted by Langmuir isotherm well $\left(r^{2}>0.858, P<0.01(n=7)\right)$ (Fig. 3, Table 2). The correlation coefficients suggest that the Langmuir isotherm model is suitable for describing the adsorption equilibrium of selenite and selenate by the binary oxide systems. The fitting data shows that the maximum
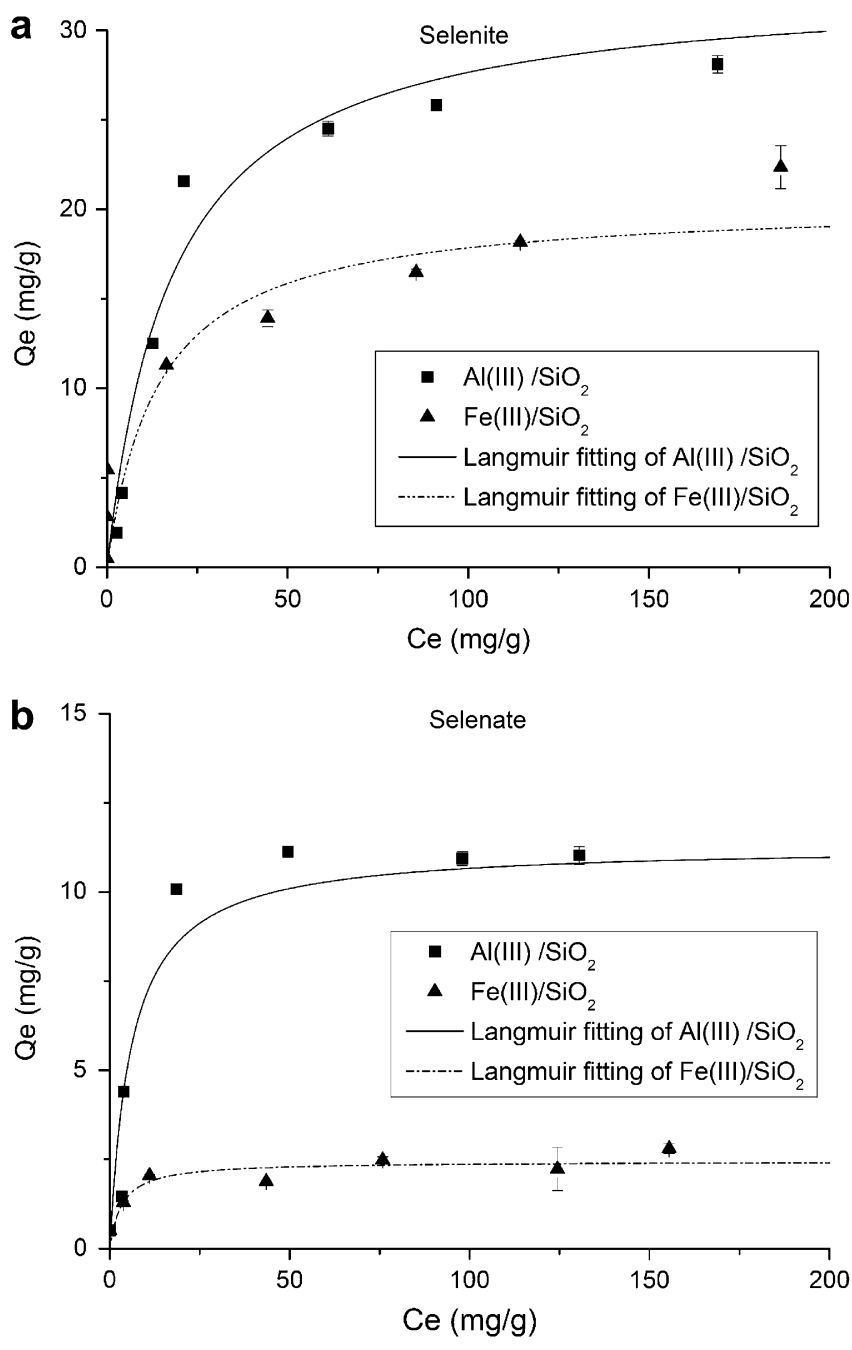

Fig. 3 - Adsorption isotherms of (a) selenite and (b) selenate on the binary oxide systems at pH $5.0,25^{\circ} \mathrm{C}$ in $0.01 \mathrm{M}$ $\mathrm{NaNO}_{3}$ as background electrolytes.

adsorption capacity $\left(\mathrm{Q}_{\max }\right)$ for selenite and selenate by $\mathrm{Al}(\mathrm{III}) /$ $\mathrm{SiO}_{2}$ was 32.7 and $11.3 \mathrm{mg} / \mathrm{g}$, and the $Q_{\max }$ for selenite and selenate by $\mathrm{Fe}(\mathrm{III}) / \mathrm{SiO}_{2}$ are 20.4 and $2.4 \mathrm{mg} \mathrm{g}^{-1}$, respectively. In consideration of the adsorption capacities for selenium species, $\mathrm{Al}(\mathrm{III}) / \mathrm{SiO}_{2}$ and $\mathrm{Fe}(\mathrm{III}) / \mathrm{SiO}_{2}$ appear to be much higher than coarse Al- or Fe-oxide coated sand (Lo and Chen, 1997;

Table 2 - The isotherm adsorption parameters of selenite and selenate on the binary oxide systems at $\mathrm{pH} 5.0$ for the Langmuir isothermal fitting model.

\begin{tabular}{|c|c|c|c|c|}
\hline System & Adsorbate & $K_{\mathrm{L}}\left(\mathrm{L} \mathrm{mg} \mathrm{g}^{-1}\right)^{\mathrm{a}}$ & $\mathrm{Q}_{\max }\left(\mathrm{mg} \mathrm{g}^{-1}\right)^{\mathrm{b}}$ & $r^{2}$ \\
\hline $\mathrm{Al}(\mathrm{III}) / \mathrm{SiO}_{2}$ & Selenite & $5.50 \times 10^{-2}$ & 32.7 & $0.983^{* *}$ \\
\hline $\mathrm{Fe}(\mathrm{III}) / \mathrm{SiO}_{2}$ & & $7.06 \times 10^{-2}$ & 20.4 & $0.876^{* *}$ \\
\hline $\mathrm{Al}(\mathrm{III}) / \mathrm{SiO}_{2}$ & Selenate & $1.68 \times 10^{-1}$ & 11.3 & $0.920^{* *}$ \\
\hline $\mathrm{Fe}(\mathrm{III}) / \mathrm{SiO}_{2}$ & & $3.03 \times 10^{-1}$ & 2.4 & $0.858^{* *}$ \\
\hline
\end{tabular}


Kuan et al., 1998). Both of the binary oxide systems can be attributed to fine particles that increase the contact between selenium species and the adsorbents.

The adsorption capacity of selenite on both binary oxide systems is more than selenate, which is consistent with the results derived from distinguishing various anion affinities based on the first acidity constant (Hayes, 1987; Hayes et al., 1988). The chemical characteristics and the geometry structure of selenite are similar to phosphate, whereas selenate is similar to sulfate (Hayes, 1987; wijnja and Schulthess, 2000), and adsorbed selenite on the both binary oxide systems is greater than selenate.

The $\mathrm{Al}(\mathrm{III}) / \mathrm{SiO}_{2}$ system shows a much greater capacity for selenite and selenate compared with the $\mathrm{Fe}(\mathrm{III}) / \mathrm{SiO}_{2}$ system, resulting from high affinity of the more positive charge of the $\mathrm{Al}(\mathrm{III}) / \mathrm{SiO}_{2}$ system for selenium oxyanions (Fig. 1). The precipitation of iron particles on $\mathrm{SiO}_{2}$ cannot increase any adsorption site, and the negatively charged surface of $\mathrm{SiO}_{2}$ increases the repulsion between selenium oxyanions and $\mathrm{SiO}_{2}$. Thus the $\mathrm{Q}_{\text {max }}$ of selenium on $\mathrm{Al}(\mathrm{III}) / \mathrm{SiO}_{2}$ is much higher than that of $\mathrm{Fe}(\mathrm{III}) / \mathrm{SiO}_{2}$ (Table 2). As for the mechanisms by which selenite and selenate are adsorbed on the binary oxide systems, previous spectroscopic studies show that selenium is adsorbed to Al- and Fe-oxides by forming inner-sphere surface complexes by ligand exchange with hydroxyl groups at the mineral surface (Peak, 2006). To study the mechanism of the adsorption process, we subjected the samples to XANES and EXAFS spectra of selenium adsorbed to the binary oxide systems.

\subsection{Adsorption kinetics}

The kinetics of adsorption that describe the solute adsorption rate governing the residence time of the sorption reaction is one of the important characteristics that define the efficiency of adsorption. Fig. 4 shows the adsorption data of selenium by the both binary oxide systems at different time intervals and the simulation of the pseudo-second-order kinetic model. Adsorption of both selenite and selenate on the binary oxide systems approach pseudo-equilibrium more rapidly than those on Al or Fe coatings on quartz sands (Lo and Chen, 1997; Kuan et al., 1998). For selenite on $\mathrm{Al}(\mathrm{III}) / \mathrm{SiO}_{2}$ and $\mathrm{Fe}(\mathrm{III}) / \mathrm{SiO}_{2}$, $95 \%$ removal of selenite was achieved within $2 \mathrm{~h}$ of contact, and the adsorption equilibrium was approached (Fig. 4a). The removal percentage for selenate individually reached 99 and $96 \%$ on $\mathrm{Al}(\mathrm{III}) / \mathrm{SiO}_{2}$ and $\mathrm{Fe}(\mathrm{III}) / \mathrm{SiO}_{2}$ in $30 \mathrm{~min}$, and the adsorption approached equilibrium too (Fig. 4b). The greater surface area and smaller particle size of both binary oxide systems raise the probability of the adsorption reactions. The kinetics data has been fitted by the zero-, first-, pseudo-second-, second-order, parabolic, and Elovich models, evaluating the $r^{2}$ and P-value, and the total fitted data was not shown. The pseudo-second-order kinetic model is the best model to describe the kinetic data in the binary oxide systems. Table 3 shows the determination coefficients $\left(r^{2}\right)$ and the other parameters obtained from the pseudo-second-order kinetic model by the plot of $t$ versus $t / q_{t}$ to determine the $V_{0}$ and $q_{e q}$ values for all the media. The pseudo-second-order model fits the kinetic data of the both binary oxide systems very well $\left(r^{2}>0.999, P<0.001, n=18\right)$. The initial adsorption rate of
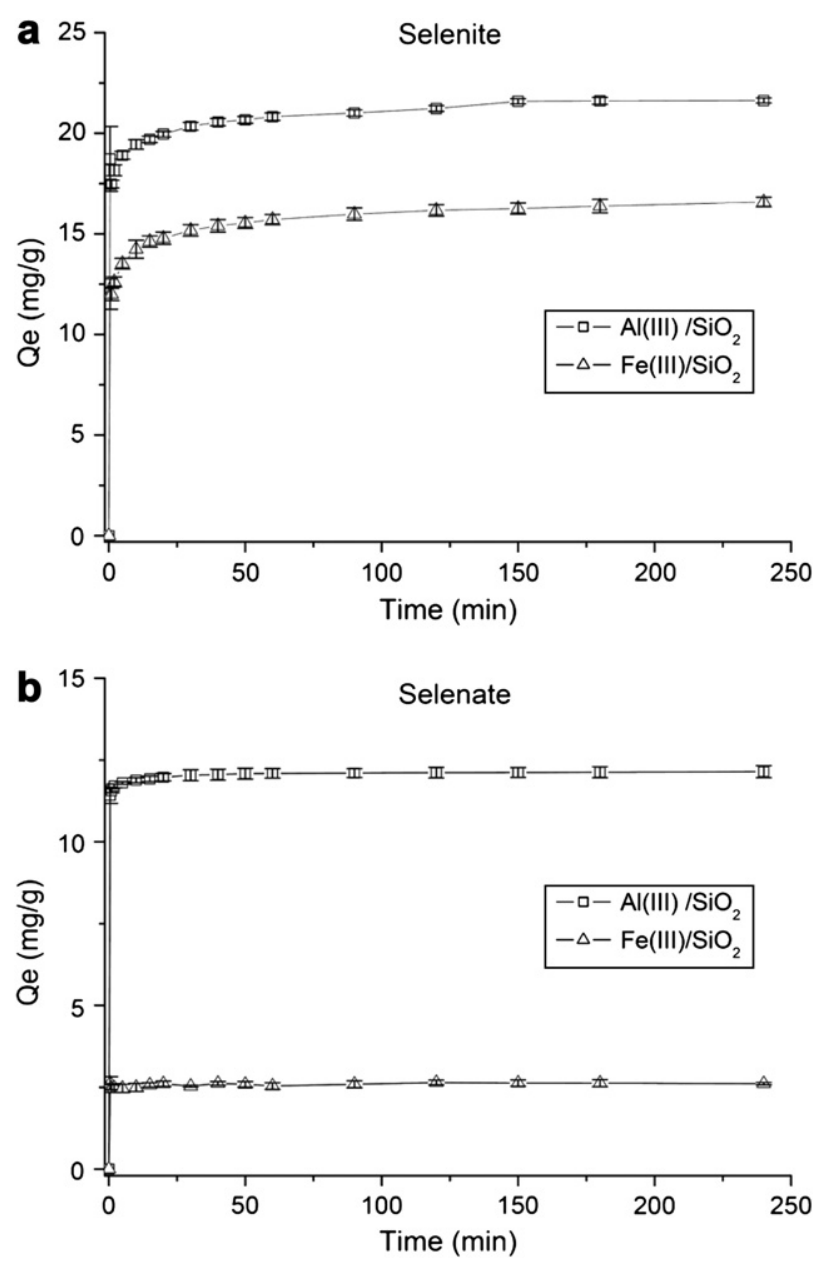

Fig. 4 - Adsorption kinetics of (a) selenite and (b) selenate on the binary oxide systems at pH 5.0, at $25^{\circ} \mathrm{C}$ in $0.01 \mathrm{M}$ $\mathrm{NaNO}_{3}$ as background electrolytes.

selenite over $\mathrm{Al}(\mathrm{III}) / \mathrm{SiO}_{2}$ is $6.25 \mathrm{mg} \mathrm{g}^{-1} \mathrm{~h}^{-1}$, which is less than that of selenate $\left(57.5 \mathrm{mg} \mathrm{g}^{-1} \mathrm{~h}^{-1}\right)$, and the rate of selenite and selenate over $\mathrm{Fe}(\mathrm{III}) / \mathrm{SiO}_{2}$ is 8.36 and $4.89 \mathrm{mg} \mathrm{g}^{-1} \mathrm{~h}^{-1}$. The fitting data shows that $\mathrm{Al}(\mathrm{III}) / \mathrm{SiO}_{2}$ has a higher affinity for selenate, and the adsorption capacity of selenate is greater than selenate on $\mathrm{Fe}(\mathrm{III}) / \mathrm{SiO}_{2}$. Unlike selenite, in which the supernatant $\mathrm{pH}$ is stable, the $\mathrm{pH}$ increases from 5.0 to 8.0 for the selenate

Table 3 - Kinetic parameters of a pseudo-second-order kinetic model fitting selenium oxyanions adsorption by the binary oxide systems at pH 5.0.

\begin{tabular}{lcccc} 
System & $\begin{array}{c}\mathrm{V}_{0} \\
\left(\mathrm{mg} \mathrm{g}^{-1} \mathrm{~h}^{-1}\right)^{*}\end{array}$ & $\begin{array}{c}\mathrm{q}_{\text {eq }} \\
\left(\mathrm{mg} \mathrm{g}^{-1}\right)\end{array}$ & $\begin{array}{c}k_{2} \\
\left(\mathrm{~g} \mathrm{mg}^{-1} \mathrm{~h}^{-1}\right)\end{array}$ & $r^{2}$ \\
\hline Selenite & & & & \\
$\mathrm{Al}(\mathrm{III}) / \mathrm{SiO}_{2}$ & 6.25 & 22.47 & $1.24 \times 10^{-2}$ & $0.999^{* * *}$ \\
$\mathrm{Fe}(\mathrm{III}) / \mathrm{SiO}_{2}$ & 8.36 & 16.57 & $3.04 \times 10^{-2}$ & $0.999^{* * *}$ \\
$\mathrm{Selenate}$ & & & & $0.999^{* * *}$ \\
$\mathrm{Al}(\mathrm{III}) / \mathrm{SiO}_{2}$ & 57.5 & 12.14 & 0.39 & $0.999^{* * *}$ \\
$\mathrm{Fe}(\mathrm{III}) / \mathrm{SiO}_{2}$ & 4.89 & 2.63 & 0.71 & \\
${ }^{*} \mathrm{~V}_{0}$ is the initial sorption rate. & & & \\
${ }^{* * *} \mathrm{P}<0.001$ ( $\left.\mathrm{n}=18\right)$. & & & \\
\hline
\end{tabular}



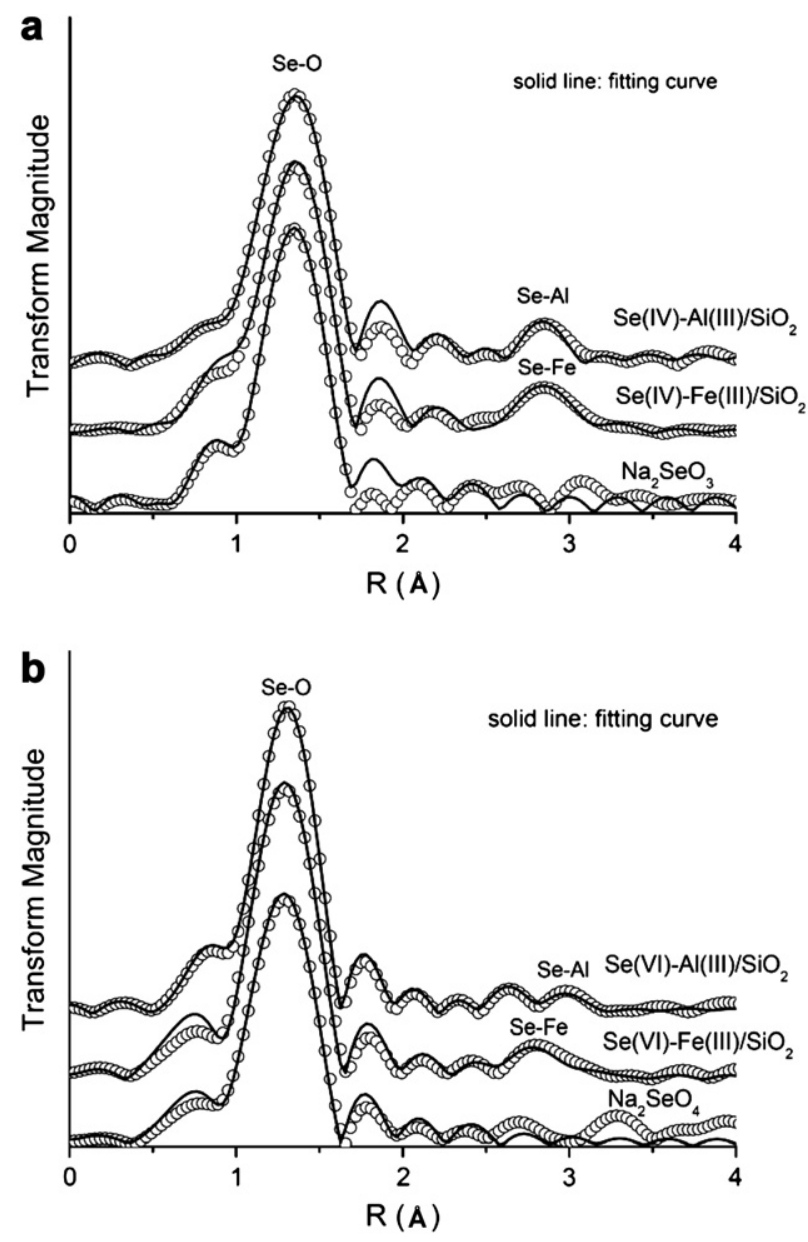

Fig. 5 - RSF profiles of EXAFS signal for selenium species standard: (a) selenite and (b) selenate sorbed on the binary oxide systems at pH 5.0. Solid lines and open circles represent fitted and experimental data, respectively.

equilibrium solution, indicating that hydroxide ions are released in the adsorption process. Since selenite strongly bonds to the metal oxide surface via the formation of stronger inner-sphere complexes, selenite takes more time to reach equilibrium in the slow process (Balistrieri and Chao, 1987; Hayes, 1987; Neal et al., 1987; Zhang and Sparks, 1990; Scott and Morgan, 1996).

\subsection{XAS data analysis}

From the adsorption reaction of the XANES, there is no change in oxidation state following interaction between the selenium species and the binary oxide systems. Fig. 5 and Table 4 show the results of Se K-edge EXAFS conducted on samples of selenite adsorbed on the binary oxide systems at pH 5.0. The radial structure functions (RSFs) of the Fourier-transformed data are shown in Fig. 5a,b. In all the selenite samples, there is clear evidence of two shells in the RSFs: a first shell Se-O (fitted with 30 at $1.72 \AA$ ) and a second shell Se-Al or Se-Fe in both binary oxide systems (Fig. 5a). The Se-O distance is in good agreement with previous EXAFS experiments conducted on selenite, which have shown Se-O bond distances of 1.68$1.72 \AA$ for aqueous and adsorbed selenite (Manceau and Charlet, 1994; Peak et al., 2006; Peak, 2006). Based on simple geometrical constraints, the best assignment of the bonding environment for selenite on $\mathrm{Al}(\mathrm{III}) / \mathrm{SiO}_{2}$ (Se-Al was fitted with 2 $\mathrm{Al}$ at $3.22 \AA$ ) at pH 5.0 is a bidentate-binuclear surface complex (the range of the bond length is $\sim 3.2 \AA$ ). This is in good agreement with previous studies (Hayes et al., 1987) of selenite adsorption on other aluminum-bearing mineral surfaces, which also reported bidentate-binuclear surface complexation. The presence of inner-sphere selenate on goethite is consistent with the work of Manceau and Charlet (1994), and they reported a similar Se-Fe bond distance of $3.29 \AA$, as compared to $3.31 \AA$ in this work (Table 4). On hydrous ferric oxide (HFO), however, they found that their data were best described with $0.4 \mathrm{Fe}$ at $2.80 \AA$ and $1.8 \mathrm{Fe}$ at $3.29 \AA$. They attributed the distance of $2.80 \AA$ to a bidentate mononuclear surface complex and the distance of $3.29 \AA$ to that of a bidentate-binuclear surface complex. The result of selenite on $\mathrm{Fe}(\mathrm{III}) / \mathrm{SiO}_{2}$ shows the distance of $3.05 \AA$ to form a bidentate mononuclear surface complex.

The local structure of selenate on the binary oxide systems was conducted by EXAFS fitting (Table 4 and Fig. 5b). In all the selenate samples, the first shell, Se-O, in the RSFs (fitted with 40 at $1.66 \AA$ ) is consistent with

Table 4 - Structure parameters of selenium chemicals and selenium oxyanions adsorbed on the binary oxide systems derived from the EXAFS spectrum fitting.

\begin{tabular}{|c|c|c|c|c|c|c|c|}
\hline \multirow[t]{2}{*}{ Sample } & \multirow[t]{2}{*}{$\mathrm{S}_{0}^{\mathrm{a}}$} & \multicolumn{3}{|c|}{ 1st shell: Se-O } & \multicolumn{3}{|c|}{ 2nd shell: Se-metal } \\
\hline & & $R(\AA)^{b}$ & $\mathrm{CN}^{\mathrm{c}}$ & $\sigma^{2}\left(\AA^{2}\right)^{\mathrm{d}}$ & $R(\AA)$ & $\mathrm{CN}$ & $\sigma^{2}\left(\AA^{2}\right)$ \\
\hline $\mathrm{Na}_{2} \mathrm{SeO}_{3}$ & 0.85 & 1.66 & 3 & 0.0018 & $* * *$ & $* * *$ & $* * *$ \\
\hline $\mathrm{Se}(\mathrm{IV})-\mathrm{Fe}(\mathrm{III}) / \mathrm{SiO}_{2}$ & 0.85 & 1.66 & 3 & 0.0019 & 3.05 & 1 & 0.0080 \\
\hline $\mathrm{Se}(\mathrm{IV})-\mathrm{Al}(\mathrm{III}) / \mathrm{SiO}_{2}$ & 0.85 & 1.66 & 3 & 0.0015 & 3.22 & 2 & 0.0012 \\
\hline $\mathrm{Na}_{2} \mathrm{SeO}_{4}$ & 0.85 & 1.72 & 4 & 0.0022 & $* * *$ & $* * *$ & $* * *$ \\
\hline $\mathrm{Se}(\mathrm{VI})-\mathrm{Fe}(\mathrm{III}) / \mathrm{SiO}_{2}$ & 0.85 & 1.72 & 4 & 0.0007 & 3.04 & 1 & 0.0073 \\
\hline $\mathrm{Se}(\mathrm{VI})-\mathrm{Al}(\mathrm{III}) / \mathrm{SiO}_{2}$ & 0.85 & 1.72 & 4 & 0.0011 & 3.32 & 1 & 0.0046 \\
\hline \multicolumn{8}{|c|}{$\begin{array}{l}\text { a Amplitude reduction factor. } \\
\text { b Interatomic distance }( \pm 0.02 \AA) \text {. } \\
\text { c Coordination number }( \pm 20 \%) \text {. } \\
\text { d Debye-Waller factor (disorder parameter). }\end{array}$} \\
\hline
\end{tabular}


previously published Se-O distances of aqueous and adsorbed selenate (Hayes et al., 1987; Peak and Sparks, 2002). The bonding length and coordination number (3.32 $\AA$ and $\mathrm{CN}=1$ ) of the Se-Al distance in the selenate sorption samples suggest that the coordination environment of selenate on the $\mathrm{Al}(\mathrm{III}) / \mathrm{SiO}_{2}$ surface is an inner-sphere surface complex in the study. However, the Se-Fe bond length (3.04 $\AA$ ) shows that selenate on $\mathrm{Fe}(\mathrm{III}) / \mathrm{SiO}_{2}$ forms bidentate mononuclear complexes (Hug, 1997; Peak and Sparks, 2002). The EXAFS fitting data shows that selenate binding to $\mathrm{Fe}(\mathrm{III}) / \mathrm{SiO}_{2}$ is stronger than to $\mathrm{Al}(\mathrm{III}) / \mathrm{SiO}_{2}$. According to the EXAFS principles, the surrounding atoms at a distance from the X-ray absorbing atom is the bond distance. The longer the bond distance is, the weaker the interaction between the center and surrounding atoms. The Se-metal bond distances for selenite and selenate for the $\mathrm{Fe}(\mathrm{III}) / \mathrm{SiO}_{2}$ system are virtually identical. The fit quality estimated accuracy of bond distances is $\pm 0.02 \AA$. Peak and Sparks (2002) indicated selenate forms only inner-sphere surface complexes on hematite but forms a mixture of outer- and inner-sphere surface complexes on goethite and HFO. The EXAFS results showed that selenate on $\mathrm{Fe}(\mathrm{III}) / \mathrm{SiO}_{2}$ formed inner-sphere complexes. Although both selenate and selenite form inner-sphere complexes on the binary oxide systems at $\mathrm{pH} 5.0$, the data suggests that selenite on the binary oxide systems forms stronger surface complexes than selenate.

\section{Conclusions}

According to the results, we suggest that Al- or Fe-oxide can modify the negative surface charge of $\mathrm{SiO}_{2}$ in the binary oxide systems, and apply the binary oxide systems to anion adsorption, selenium oxyanions. From this study, we observed that $\mathrm{Al}(\mathrm{III}) / \mathrm{SiO}_{2}$ and $\mathrm{Fe}(\mathrm{III}) / \mathrm{SiO}_{2}$ are efficient at removing selenium oxyanions from aqueous solutions. However, the stronger association between $\mathrm{Al}(\mathrm{III})$ and the $\mathrm{SiO}_{2}$ surface causes the overall surface charge to be more positive than $\mathrm{Fe}(\mathrm{III}) /$ $\mathrm{SiO}_{2}$, and the selenium adsorption capacity of $\mathrm{Al}(\mathrm{III}) / \mathrm{SiO}_{2}$ to be more than $\mathrm{Fe}(\mathrm{III}) / \mathrm{SiO}_{2}$. At $\mathrm{pH}$ 5.0, selenite on $\mathrm{Al}(\mathrm{III}) / \mathrm{SiO}_{2}$ and $\mathrm{Fe}(\mathrm{III}) / \mathrm{SiO}_{2}$ forms inner-sphere complexes, including bidentate and monodentate ones, respectively. However, selenate on $\mathrm{Al}(\mathrm{III}) / \mathrm{SiO}_{2}$ forms weaker inner-sphere monodentate complexes, the same as selenate on $\mathrm{Fe}(\mathrm{III}) / \mathrm{SiO}_{2}$. According to the bond distance of selenate, the higher affinity between selenate and Fe causes the shorter bond distance. The findings obtained in the present study are of fundamental significance in advancing the frontiers of knowledge on geochemistry of the binary oxide systems.

\section{Acknowledgments}

We thank the National Science Council, Taiwan for the financial support (NSC 91-2313-B-002-361, 92-2313-B-002-090, 93-2313-B-002-008, 94-2313-B-002-091, 95-2313-B-002-041 and 96-2313-B-002-021) of nano-particle projects.

\section{REFERENCES}

Ankudinov, A.L., Ravel, B., Rehr, J.J., Conradson, S.D., 1998. FEFF8. 20: real-space multiple-scattering calculation and interpretation of $\mathrm{x}$-ray-absorption near-edge structure. Phys. Rev. B 58, 7565-7576.

Balistrieri, L., Chao, T.T., 1987. Adsorption of selenium by amorphous iron oxyhydroxide and manganese dioxide. Geochim. Cosmochim. Acta 54, 739-751.

Cernohorsky, M., 1960. The ratio method for absolute measurements of lattice parameters with cylindrical cameras. Acta Crystallogr 13, 823-826.

Frankenberger Jr., W.T., Benson, S. (Eds.), 1994. Selenium in the Environment. Marcel Dekker, New York, p. 472.

Ghosh, M.M., Cox, C.D., Yuan-Pan, J.R., 1994. Adsorption of selenium on hydrous alumina. Environ. Prog 13, 79-88.

Goh, K.H., Lim, T.T., Dong, Z., 2008. Application of layered double hydroxides for removal of oxyanions: a review. Water Res. 42 , 1343-1368.

Hayes, K.F., 1987. Equilibrium, spectroscopic and kinetic studies of ion adsorption at the oxide/aqueous interface. $\mathrm{PhD}$ dissertation. Stanford University, CA.

Hayes, K.F., Roe, A.L., Brown Jr., G.E., Hodgson, K.O., Leckie, J.O., Parks, G.A., 1987. In situ X-ray adsorption study of surface complexes: selenium oxyanions on $\alpha-\mathrm{FeOOH}$. Science 238 , 783-786.

Honeyman, B.D., 1984. Cation and anion adsorption at the oxide/solution interface in systems containing binary mixtures of adsorbents. PhD dissertation. Stanford University, Stanford, CA.

Hug, S.J., 1997. In Situ Fourier transform infrared measurements of sulfate adsorption on hematite in aqueous solutions. J. Colloid Interface Sci. 188, 415-422.

Inorganic Crystal Structure Database (ICSD), 1981. In: Kurchhof, A., Pebler, A., Warkenten, E. (Eds.), Gmelin-Institut für Anorganische Chemie. Springer-Verlag, Berlin.

Jacobs, L.W., 1989. Selenium in Agriculture and the Environment. American Society of Agronomy, Inc., Madison, WI.

Jang, M., Shin, E.W., Park, J.K., Choi, S.I., 2003. Mechanisms of arsenate adsorption by highly-ordered nano-structured silicate media impregnated with metal oxides. Environ. Sci. Technol 37, 5062-5070.

Jordan, N., Lomenech, C., Marmier, N., Giffaut, E., Ehrhardt, J.J., 2009a. Sorption of selenium(IV) onto magnetite in the presence of silicic acid. J. Colloid Interface Sci. 329, 17-23.

Jordan, N., Lomenech, C., Marmier, N., Giffaut, E., Ehrhardt, J.J., 2009b. Competition between selenium (IV) and silicic acid on the hematite surface. Chemosphere 75, 129-134.

Koningsberger, D.C., Prins, P., 1998. X-ray Absorption: Principles, Applications, Techniques of EXAFS, SEXAFS, and XANES. John Wiley \& Sons, New York.

Kuan, W.H., Lo, S.L., Wang, M.K., Lin, C.F., 1998. Removal of Se(IV) and $\mathrm{Se}(\mathrm{VI})$ from water by aluminum-oxide-coated sand. Water Res. 32, 915-923.

Kuan, W.H., Lo, S.L., Wang, M.K., 2004. Modeling and electrokinetic evidences on the processes of the $\mathrm{Al}(\mathrm{III})$ sorption continuum in $\mathrm{SiO}_{2(\mathrm{~s})}$ suspension. J. Colloid Interface Sci. 272, 489-497.

Lenz, M., Van Hullebusch, E.C., Hommes, G., Corvini, F.F.X., Lens, P.N.L., 2008. Selenate removal in methanogenic and sulfate-reducing upflow anaerobic sludge bed reactors. Water Res. 42, 2184-2194.

Lo, S.L., Chen, T.Y., 1997. Adsorption of Se(IV) and Se(VI) on an iron-coated sand from water. Chemosphere 35, 919-930.

Lytle, F.W., Greefgor, R.B., Sandstrom, D.R., Marques, E.C., Wong, F., Spiro, C.L., Huffman, G.P., Huggins, F.E., 1984. Measurement of soft X-ray absorption spectra with 
a fluorescent ion chamber detector. Nucl. Instrum. Methods Phys. Res. A 226, 542-548.

Manceau, A., Charlet, L., 1994. The mechanism of selenate adsorption on goethite and hydrous ferric oxide. J. Colloid Interface Sci. 168, 87-93.

Meng, X., Letterman, R.D., 1993. Effect of component oxide interaction on the adsorption properties of mixes oxides. Environ. Sci. Technol 27, 970-975.

Meng, X., Letterman, R.D., 1996. Modeling cadmium and sulfate adsorption by $\mathrm{Fe}(\mathrm{OH})_{3} / \mathrm{SiO}_{2}$ mixed oxides. Water Res. 30, 2148-2154.

Mikkelsen, R.L., Page, A.L., Bingham, F.T., 1989. Factors affecting selenium accumulation by agricultural crops. In: Jacobs, L.W. (Ed.), Selenium in agriculture and the environment. Soil Science Society of America. SSSA Special Publication 23, Madison, WI, pp. 65-94.

Neal, R.H., Sposito, G., Holtzclaw, K.M., Traina, S.J., 1987. Selenite adsorption on alluvial soil: I. Soil composition and pH effects; II. Solution composition effects. Soil Sci. Soc. Am. J 51, 1161-1169.

Newville, M., 2001. IFEFFIT: interactive XAFS analysis and FEFF fitting. J. Synchrotron Radiat 8, 322-324.

Peak, D., 2006. Adsorption mechanisms of selenium oxyanions at the aluminum oxide/water interface. J. Colloid Interface Sci. 303, 337-345.

Peak, D., Sparks, D.L., 2002. Mechanisms of selenate adsorption on iron oxides and hydroxides. Environ. Sci. Technol 36 1460-1466.

Peak, D., Saha, U.K., Huang, P.M., 2006. Selenite adsorption mechanisms on pure and coated montmorillonite: an EXAFS and XANES spectroscopic study. Soil Sci. Soc. Am. J 70, 192-203.
Ravel, B., Newville, M., 2005. ATHENA, ARTEMIS, HEPHAESTUS: data analysis for X-ray absorption spectroscopy using IFEFFIT. J. Synchrotron. Radiat. 12, 537-541.

Rehr, J.J., Albers, R.C., 2000. Theoretical approaches to x-ray absorption fine structure. Rev. Mod. Phys. 72, 621-654.

Saha, U.K., Liu, C., Kozak, L.M., Huang, P.M., 2004. Kinetics of selenite adsorption on hydroxyaluminum- and hydroxyaluminosilicate-montmorillonite complexes. Soil Sci. Soc. Am. J 68, 1197-1209.

Scott, M.J., Morgan, J.J., 1996. Reactions at oxide surfaces. II. Oxidation of Se(IV) by synthetic birnessite. Environ. Sci. Technol 30, 1990-1996.

Sparks, D.L., 2003. Environmental Soil Chemistry, second ed. Academic Press, Amsterdam.

Stumm, W., 1992. Chemistry of the Solid-Water Interface. John Wiley \& Sons, New York.

Stumm, W., Wollast, R., 1990. Kinetics of the surface-controlled dissolution of oxide minerals. Rev. Geophys. 28, 53-69.

Wijnja, H., Schulthess, C.P., 2000. Vibration spectroscopy study of selenate and sulfate adsorption mechanisms on $\mathrm{Fe}$ and $\mathrm{Al}$ (hydr)oxide surfaces. J. Colloid Interface Sci. 229, 286-297.

Zhang, P., Sparks, D.L., 1990. Kinetics of selenate and selenite adsorption/desorption at the goethite/water interface. Environ. Sci. Technol 24, 1848-1856.

Zhang, N., Lin, L.S., Gang, D., 2008. Adsorptive selenite removal from water using iron-coated GAC adsorbents. Water Res. 42, 3809-3816.

Zhao, L., Zhao, G.H., Du, M., Zhao, Z.D., Xiao, L.X., Hu, X.S., 2008. Effect of selenium on increasing free radical scavenging activities of polysaccharide extracts from a Se-enriched mushroom species of the genus. Eur. Food Res. Technol 226, 499-505. 